cerumen completes the closure of the already partially closed canal, and the consequent deafness directs attention to the ear. So long as the meatus can be kept clear of secretion by oft-repeated syringing, it is undoubtedly better not to interfere any further; but there are two conditions under which an attempt should be made to remove these growths,-1st, when behind the exostosis there is a perforation of the tympanic membrane, a polypus growing from the lining membrane of the tympanum (the protrusion of some part of the polypus beyond the exostosis will afford evidence of its existence), and thus preventing the free egress of discharge from that cavity, inducing symptoms of cerebral irritation, and so threatening life; 2nd, when the exostosis, by completely closing the auditory canal, causes intense deafness.

The removal of exostoses in the external auditory canal is beset with difficulties. The very position of the growths makes it necessary that all work must be done under light reflected from a mirror worn on the forehead of the operator. To keep this light steady, the patient's head must be absolutely motionless, and the surgeon's head must be so as well. Again, the size of the canal not only limits the movements of instruments, but also their use to but few, and any bleeding checks all proceedings until such bleeding can be stopped. Moreover, the intense hardness of the exostosis does not facilitate matters. There are two modes of operating which are deserving of especial mention. The first was originally suggested and successfully practised by Dr. Thos. E. Clarke, of Bristol, in 1873, in a case of a large exostosis which almost filled the meatus. Three needles were introduced into the growth, two at the base and one at the anterior edge. Through these needles a continuous current of electricity from six pairs of plates of a Stöhrer's battery was passed for three minutes. Fourteen days afterwards this was repeated; and three weeks later the growth was so loose as to be readily extracted, and the patient made a very good recovery. Since Dr. Clarke's case was pub. lished, in adopting similar measures, owing to the extreme hardness of the bone, I have found it convenient to drill holes into the base of the tamour to permit of the introduction of the needles; and I can testify to the success which attends this plan of removing bony growths. But I have to relate a most unfortunate mishap which occurred upon one occasion, when every precaution (so far as could be foreseen) was used. The case was one in which there was a polypus behind the exostosis, and unpleasant symptoms of cerebral irritation made the operation necessary. Two needles were inserted at the base of the tumour, and the current was passed for two minutes. The patient, a healthy man thirty years of age, suffered a good deal of pain during the night after the operation; and on awaking the next morning the facial muscles on the side operated apon were paralysed. This happened in November, 1874, and the power of movement up till now has been only partially regained. This accident must have occurred from one of two causes : either it was the immediate consequence of the electricity as applied, or else it was due to inflammation in the tympanic cavity set up by the operation. For myself, I am satisfied that the lattor explanation is the correct one. We know how frequently acute inflammation in the tympanum will produce paralysis of the muscles supplied by the portio dura, affecting as it does that part of the nerve in the aqueduct of Fallopius; and we do not as yet know that an electric current passed as was done in this case (so that the course of the current was at a considerable distance from the nerve) is capable of causing such an effect; and again, if the current had immediately paralysed the muscles, the paralysis would have occurred during the operation, and certainly on the evening of the day of the operation there was no facial paralysis. I have thought it right to publish this account that it may serve as a caution in the future to others besides myself in dealing with similar cases, but how far we shall be justified in abandoning this method of treatment because an unfortunate accident happened in a single case, each one must judge for himself. The removal of exostoses in the external auditory canal is not sufficiently common to supply a very large experience, but I must confess to have kept on the safe side since this case, and to have employed another method, which is entirely free from the slightest risk of any like catastrophe. It consists in grinding the bone away, and the most satisfactory appliance for this purpose I find to be the drill which is in common use among dentists. The variety of steel instruments which can be fixed to this, and the perfect command with which the instrument can be directed, render this an especially convenient instrument. Reflected light of course must bo employed, the patient must be made insensible to pain, and a third person must turn the lathe, or cease turning, according to the directions given him at the time; with such precautions I know of no such ready method of destroying these bony growths when their removal becomes imperative.

\section{ON PROFESSIONAL MUSCULAR ATROPHY.}

\section{Br Dr. E. ONIMUS,}

LAUREATE OF THE PARIS ACADEMT OF SCTENCES, MBMBER OF THE PAEIS SOCIETY OF BIOLOGT, ETC.

Activity of muscles determines the development and energy of muscular fibres, and the general law is that the more a muscle works the larger and the more powerful it gets. This law, however, has its limits, and I have just observed a certain number of cases in which the exaggerated work of certain muscular groups, far from producing hypertrophy, induced, on the contrary, a condition of considerable atrophy.

These cases are observed only in individuals who, through the nature of their trade or work, are obliged to contract the same muscles constantly. Through excess of activity, irritation of the murcular fibres supervenes. Thus, in a man employed in a draper's establishment, and whose business was to replace the unfolded goods on their shelves, there supervened, little by little, a most remarkable atrophy of the deltoid muscles of both sides. And, indeed, it was these muscles which were constantly actively employed in performing this special work.

In a workman employed in a tannery, who was every day for eleven hours at work, and always felt aching and fatigued after his day's labour, there likewise supervened marked muscular atrophy, confined to certain muscles. In order to prepare the skins, he was to perform with both arms a forward and backward movement, which necessitated especially the action of the muscles of the shoulder, so that these were the first to be affected, and are at present almost completely atrophied. The wasting away is almost the same in both arms, as both were in action during the man's work, whereas, in respect to the legs, the right one alone was obliged to support the whole weight of the body. Consequently, with the lower limbs, the right leg is the only one that has wasted; it is one-half smaller than the other, and the affected muscles are those the action of which was the most constant, such as the rectus femoris, vastus externus, and vastus internus.

In the beginning, the patients complain especially of prostration, of weakness even in the morning on getting out of bed. They feel-particularly at the outset of the disease - intense, darting, intermittent pains. Before atrophy is well-marked there always exists more or less temporary contraction of the muscles.

When wasting has once begun, it follows a most rapid course if the patient continues to fatigue his muscles.

Almost always this affection is mistaken for progressive muscular atrophy, but it differs from it in its course and in a great many of the symptoms. 1st. The muscles which are the first to be affected are generally the largest ones, and particularly those in the neighbourhood of the shoulder-joint. 2nd. The pain and cramps at the outset are also a distinctive sign. 3rd. These cases of wasting amend rather rapidly under the influence of rest and the use of constant and continuous electric currents.

Recently I observed one case which it was most difficult to differentiate from progressive muscular atrophy, as the atrophied muscles were the same as those which are the first affected in this latter affection. They were the muscles of the thenar eminence, and chiefly the adductor pollicis. The patient was an enameller, who had to hold an object all day between his thumb and index-finger. He first got cramps in the thumb, which suggested the idea of scrivener's palsy, then tremor of the thumb, on account of the fibrillar contractions, and, lastly, atrophy. Under the influence of treatment there was a rapid amendment, 
which showed that the case was really one of professional muscular atrophy, and not commencing progressive muscular atrophy.

Paris.

\section{dy}

\section{HOSPITAL PRACTICE, BRITISH AND FOREIGN.}

Nulla autem est alia pro certo noscendi via, nisi quamplurimas et morborum et dissectionum historias, tum aliorum, tum proprias collectas habere, $\mathrm{e}$ inter se comparare.-MoBgagr I De Sed. et Caus. MLorb., lib. iv. Procminm.

\section{UNIVERSITY COLLEGE HOSPITAL.}

THREE CASES OF EXTENSIVE EPITHELIOMA INVOLVING THE LOWER JAW ; REMOVAL BY SECTION OF THE BONE AND THE GALVANIC ECRASEUR.

(Under the care of Mr. Christopher HeATH.)

THE following case, for the notes of which we are indebted to Mr. Gould, is a continuation of the series we commenced last week.

CASE 2. Epithelioma of tongue, involving lower jaw; removal of growth and three inches of the lower jaw; wound healed; death from broncho-pneumonia. - E. B-, aged fifty-one, a printer, was admitted Nov.19th, 1875. He was a pale, delicatelooking man, with an anxious expression; and complained of pain in the mouth and inability to protrude the tongue. The tip of the tongue was found to be fixed just behind the incisor teeth, and a hard ovoid mass was felt between the tongue, jaw, and hyoid bones, the larger end being forwards. This mass was about the size of a pigeon's egg, smooth, with a small rounded nodule on the left side, firm, elastic, implicating the tip and the anterior fourth of the tongue but not reaching to the surface, and firmly fixed to the lower jaw. Opposite the left canine and bicuspid teeth was a raised ulcer with firm granulations, and opposite to this was a depressed ulcer in the gums of similar character. Nothing of this growth could be felt from the outside; there was one enlarged gland below the left angle of the jaw. There was soreness in the ulcers, and occasional shooting pains round the tip of the tongue; the pain quite prevented all mastication; no trouble in swallowing. Manipulation of the growth greatly relieved the pain.

The history was that in July last the man noticed a number of small "boils" under the tongue, which broke, and did not trouble him much. These "boils" seemed to run together, and in August he noticed that in yawning he cracked the floor of the mouth where these boils were; this fissure was very sore indeed, but the pain was relieved by alum. He was then free from trouble till Oetober, when he noticed a lump beneath the tongue, which gradually increased in size. He had some slight but indistinct recollection of running a pipe into the left side of the mouth, but he had forgotten exactly when. Eight years ago he had hæmoptysis. No history of cancer in the family.

On Nov, 24th, while under chloroform, the parts of the lower jaw and tongue that were involved were removed. Mr. Heath made an incision down the middle line of the lower lip, and dissected back the flaps from the bone. A hole was then drilled through the jaw, outside each canine tooth, and the bone sawn through just inside these holes; the saw was directed straight back on each side, and not at right angles to the plane of the bone. The wire of the galvanic écraseur was then put round the tongue and the muscles beneath it, well behind the disease. The division of the tissues was made in four minutes. An attempt was made to bring the two pieces of the jaw together, but this was found to be impossible. (It was for this purpose that the holes had been drilled.) Three hare-lip pins were passed through the lip, and a thread through the tongue was fastened to one of the pins for the first seven hours.

The patient was fed by means of a soft catheter, which was pasefd to the back of the mouth over the tongue, which was tilted up against the hard palate, and had to be drawn down by the thread fastened to it to allow the catheter to pass; he had eight ounces of brandy, four eggs, and beef-tea per diem. The wound in the lip healed by first intention, except a small aperture at the lower end, through which stained and then clear watery fluid drained on to a bib of oakum tied on round the neck. The top pin was removed on the 27 th, and the other two on the 28 th. The tongue became at first a good deal swollen, and was covered with a soft yellowish slough, which had separated on Dec. 2nd. The tongue was painted every morning and evening with glycerine and carbolic acid, and the mouth washed out several times a day with terebene lotion. For the first few days the patient's chief complaint was of the sticky mucus which collected in the mouth, and the gland under the jaw was tender the day after the operation. On the third day he had a slight attack of diarrhca.

On Dec. 1st the sloughs on the gums had separated leaving the edge of the sawn jaw exposed, and this hurt the tongue and made swallowing difficult. Next day this was much better, and he was able to feed himself, by means of a feeder with a soft spout, but in the evening there was a little bæmorrhage from the floor of the inouth, easily stopped by syringing with cold water. Up to this time the temperature had not been above $99 \cdot 2^{\circ}$, with pulse of 100 , of good strength. For two days he had complained of cough, and coarse moist râles were heard on the left side of the chest, for which a poultice was applied, and a turpentine stupe on Dec. 2nd.

3rd.-Temperature $100.1^{\circ}$; pulse 100 . Ordered a mixture containing ammonia, squill, and senega. He complained of pain close to the condyles of the jaw.

4th.-'Temperature rose to $102^{\circ}$; pulse 120 . Loud grating friction was heard all over left back. Respiration 30 .

5th.-Temperature $103 \cdot 4^{\circ}$; pulse 128 ; respiration 32 . He had a rigor which lasted a quarter of an hour in the morning. Not so well; complained of pain in his chest and dyspnœa.

7 th. - Temperature $1008^{\circ}$; pulse 148 ; respiration 50. Patient had a disturbed night. He was weaker, more cyanosed, and had considerable dyspncea. Sonorous râles over right lung; same over left, with soft friction; no dulness. Fluid continued to flow through the drain at chin. At 3 P.M. to-day he died asphyxiated, exactly thirteen days after the operation.

At the post-mortem examination old adhesions were found in both pleuræ, with a little recent lymph on the right pleura, and a considerable quantity on the left. Both lungs were very much congested, and in the left base some patches of pneumonia were found. There was nothing to note about the other viscera. The end of the tongue was found to be healed over, and the tissues at the floor of the mouth were cicatrised, but there was still a small interval at the lower part of the incision in the lower lip. The cut surfaces of the bone were bare, separated by an interval of about an inch.

The growth in the tongue was examined microscopically by Mr. Gould, and proved to be epitheliomatous, but without "nests" of cells, and was just like the growth in Case 1. There was no apparent recurrence in the mouth, and sections of tongue and the tissues of the floor of the mouth and gums taken after death appeared quite free from the growth.

These two cases were remarkably similar, but the first was by far the more serious, and appeared to be scarcely amenable to treatment. The bloodless removal of the tongue, with all the diseased sublingual tissues (including the muscles and salivary glands), was readily accomplished by means of the galvanic écraseur when the symphysis of the jaw had been isolated with the saw. Although in these cases three inches of the jaw were removed, the halves of the bone were generally approximated by the action of the muscles, and therefore in the second case Mr. Heath endeavoured to bring the halves of the jaw together at once with wire, having been careful to apply the saw at such an angle that the bones should fit accurately. It was found, however, impracticable to bring the parts into apposition without undue strain upon the articulations, and the attempt was abandoned. Nothing could be more satisfactory than the patient's progress in the first case, his pain being completely relieved, and so far a perfect cure having resulted. The second patient fell a victim to the late severe weather dying of bronchitis, when the greater part of the wound was healed. 